\title{
Upper abdominal surgery: does a lung function test exist to predict early severe postoperative respiratory complications?
}

\author{
G. Barisione*, S. Rovida**, G.M. Gazzaniga+, L. Fontana*
}

Upper abdominal surgery: does a lung function test exist to predict early severe postoperative respiratory complications? G. Barisione, S. Rovida, G.M. Gazzaniga, L. Fontana. C ERS Journals Ltd 1997.

ABSTRACT: We evaluated the capacity to predict severe respiratory complications (SRCs) following upper abdominal surgery (UAS) by using the results of a respiratory questionnaire and preoperative pulmonary function tests.

Lung volumes, flows and transfer factor of the lung for carbon monoxide ( $T \mathrm{~L}, \mathrm{CO}, \mathrm{sb})$ were assessed in 361 consecutive adult patients ( 248 males and 113 females). SRCs were diagnosed $24 \mathrm{~h}$ after UAS by clinical examination and chest radiography. Univariate and stepwise multiple logistic regression analyses were performed to estimate the odds ratio (OR) and $95 \%$ confidence interval $(95 \% \mathrm{CI})$ of each single input variable, and to determine which indices best predicted outcome.

These patients had a $1 \%$ mortality rate and $14 \%$ incidence of SRCs, with a male:female ratio of 0.86 . The best predictors for SRCs by multiple analysis were: preoperative current hypersecretion of mucus $(\mathrm{OR}=133 ; \mathrm{p}<0.0001)$; an increase in residual volume $(\mathrm{RV})(\mathrm{OR}=3.11 ; \mathrm{p}=0.01)$; and, to a lesser extent, low percentage of predicted values both of forced expiratory volume in one second (FEV1\% pred) and $T L, C O$, sb. The algorithm thus obtained (logit $\theta$ ) was extremely sensitive $(84 \%)$, specific $(99 \%)$, and accurate $(95 \%)$ for preoperative prediction of SRCs.

We have found that preoperative current hypersecretion of mucus and pulmonary hyperinflation, and to a lesser extent percentage predicted values both of forced expiratory volume in one second and transfer factor of the lung for carbon monoxide, have a significant predictive capacity for severe respiratory complications following upper abdominal surgery.

Eur Respir J 1997; 10: 1301-1308.
*Divisione di Medicina del Lavoro, Laboratorio di Fisiopatologia Respiratoria, Ospedale S. Martino, Genova, Italy. **Istituto di Statistica Medica e Biometria, Università di Genova, Genova, Italy. ${ }^{+1}$ a Divisione di Chirurgia Generale, Ospedale S. Martino, Genova, Italy.

Correspondence: G. Barisione, Divisione di Medicina del Lavoro, Laboratorio di Fisiopatologia Respiratoria (Pad.7/p.t.), Azienda Ospedaliera "Ospedale S. Martino di Genova" e Cliniche Universitarie Convenzionate, Largo R. Benzi 10, 16132 Genova, Italy

Keywords: Mucous hypersecretion transfer factor for carbon monoxide pulmonary hyperinflation forced expiratory volume in one second respiratory complications upper abdominal surgery

Received: May 21996

Accepted after revision February 81997
Since 1910, it has been well-known that patients undergoing upper abdominal surgery (UAS) generally develop a severe pulmonary restrictive pattern [1], and carry a high risk of postoperative respiratory complications [2-4]. The most important factors determining the degree of postoperative impairment of ventilation and gas exchange are the site of operation, the age, and clinical status of the patient [5]. Forced vital capacity (FVC) and peak flows are often reduced to half, and the functional residual capacity (FRC) to below $70 \%$ of the preoperative values [5]. These effects may not be restored even by the fifth postoperative day [5]. The reduced FVC and the reduction of FRC are mainly a consequence of an impaired diaphragmatic function [6]. Furthermore, the risk for postoperative respiratory complications decreases with the distance of the surgical incision from the diaphragm $[7,8]$.

Several studies have tried to determine the incidence of postoperative respiratory complications of UAS, and the estimates vary widely. The majority of investigations have focused on subclinical complications, i.e. radiographic evidence of atelectasis, with or without pleural fluid. With this broader definition of complication, the incidence of postoperative complications of UAS is approximately $25-75 \%[9,10]$.

In this paper, we examine the relationship between preoperative respiratory symptoms and physiology, and postoperative risk of severe respiratory complications (SRCs) in patients undergoing UAS. In particular, we will address the question: "Is there a functional best test to predict the postoperative morbidity and mortality in the high-risk pulmonary patient group?"

\section{Methods}

\section{Subjects and definition of terms}

We evaluated 361 adult Caucasian patients of European descent, admitted for laparotomy to our hospital, between January 1994 and June 1995. Standard preoperative posteroanterior (PA) and laterolateral (LL) view chest radiograph images were obtained. A trained respiratory function technician administered a questionnaire that determined patient identification, age, sex, 
smoking history, previous pulmonary problems, and the presence of cough, dyspnoea, chest pain, or discomfort and wheezing. Chronic phlegm (hypersecretion of mucus) was defined as sputum production for three or more months of the year. The degree of dyspnoea was recorded using the Borg scale for breathlessness [11]. Lifetime nonsmokers were defined, in accordance with the American Thoracic Society (ATS) standardized respiratory questionnaire [12], as having smoked fewer than 20 packs of cigarettes or $340 \mathrm{~g}$ of tobacco in a lifetime, or less than one cigarette a day for a year. Former smokers were those who exceeded this amount of tobacco consumption but had stopped smoking at least 1 month prior to evaluation. The patient's standing height (stature) and weight were also registered. Weight was expressed as body mass index $(\mathrm{BMI})\left(\mathrm{kg} \cdot \mathrm{m}^{-2}\right)$, and patients were then categorized as normal $\left(\leq 24.9 \mathrm{~kg} \cdot \mathrm{m}^{-2}\right)$, slightly $\left(25-29.9 \mathrm{~kg} \cdot \mathrm{m}^{-2}\right)$, moderately $\left(30-40 \mathrm{~kg} \cdot \mathrm{m}^{-2}\right)$, or severely $\left(>40 \mathrm{~kg} \cdot \mathrm{m}^{-2}\right)$ obese [13].

\section{Lung volumes and forced ventilatory flows}

After receiving informed consent, patients underwent complete pulmonary physiological evaluation, following a protocol approved by our human subjects institutional review board. All measurements were performed at sea level in our laboratory between 08:00 and 11:00 h. Subjects were in a resting, postprandial state and refrained from smoking for at least $24 \mathrm{~h}$.

Forced expiratory volume in one second (FEV1), FVC, slow inspiratory vital capacity (IVC), peak expiratory flow (PEF), and instantaneous expiratory flows with $50 \%$ and $25 \%$ of FVC remaining to be expired (MEF50\% and MEF25\%), were measured with a Fleisch No. 3 heated pneumotachograph (Cosmed Altair 1000; Cosmed s.r.l., Pavona di Albano, Italy). The volumes were obtained by electrical integration of flow signal. Total lung capacity (TLC), FRC, and residual volume (RV) were measured using an open-circuit, multibreath, nitrogen wash-out method (Cosmed Altair 4000; Cosmed s.r.1.). All equipment used met both ATS [14] and European Respiratory Society (ERS) recommendations [15] for spirometry and lung volumes. Reference values for spirometry and lung volumes were those dictated by the 1993 ERS official statement [15].

Values below the fifth percentile were taken as below the expected range (below the lower limit of normal) and those above the fifth percentile were taken as within the expected range $(95 \%$ confidence interval $(95 \%$ CI) method). The allowance for subjects of more than 70 yrs of age was obtained by linear extrapolation from the age of $70 \mathrm{yrs}$.

We categorized the abnormal functional patterns of patients on the basis of these tests as follows: 1) obstructive, when FEV1/IVC ratio was below the normal range; 2) restrictive, when TLC was less than the lower limit of normal; 3) mixed, when both abnormalities were concomitantly present in the same subject [16]. The degree of reversibility to salbutamol $(200 \mu \mathrm{g})$ of an obstructive disorder was assessed after $15 \mathrm{~min}$, by relating the change of FEV1 $(\triangle \mathrm{FEV} 1)$ observed to the mean level calculated between the value pre- and post- salbutamol (i.e. $100 \cdot \Delta \mathrm{x} / \overline{\mathrm{x}}$ ), as suggested by CoTES [17]. The drug was inhaled from a metered-dose inhaler via a spacing device (Volumatic $\AA$; Allen \& Hanbury, Uxbridge, UK). The bronchodilator responsiveness were categorized as follows: 1) not responsive $(<12 \%) ; 2)$ responsive $(\geq 12 \%)$ [16].

Five days before surgery and during the postoperative course, all patients with obstructive or mixed defect were receiving theophylline intravenously $\left(5 \mathrm{mg} \cdot \mathrm{kg}^{-1}\right.$ daily, checking serum level after $48 \mathrm{~h}$ ), and inhaled salbutamol (800 $\mu \mathrm{g}$ daily). All patients had received a prophylactic antibiotic.

\section{Transfer factor}

Transfer factor (diffusing capacity) of the lung for carbon monoxide was determined by the single breath method of Forster et al. [18] (TL,CO,sb), using a Cosmed Altair 4000 analyser system (Cosmed s.r.l.). All subjects with a basal FEV1/IVC ratio $<50 \%$ received a $200 \mathrm{\mu g}$ inhaled dose of salbutamol $15 \mathrm{~min}$ before the test. All measurements were expressed in standard international (SI) units ( $\left.\mathrm{mmol} \cdot \mathrm{min}^{-1} \cdot \mathrm{kPa}^{-1}\right)$ and represented the average $(\overline{\mathrm{x}})$ of two determinations, which met the ERS criteria for acceptability and were within $10 \%$ [19]. The interval between the measurements was at least 4 min. Patients with normal spirometry and lung volumes, but abnormal TL,CO,sb values, were categorized as having "isolated abnormal transfer factor".

\section{Anaesthesia technique}

All patients underwent general anaesthetic in conjunction with assisted ventilation. Anaesthesia was provided with intravenous propofolol $\left(10 \mathrm{mg} \cdot \mathrm{kg}^{-1}\right.$ body weight (bw)), atropine $\left(7 \mu \mathrm{g} \cdot \mathrm{kg}^{-1} \mathrm{bw}\right)$, promethazine $(0.7$ $\left.\mathrm{mg} \cdot \mathrm{kg}^{-1} \mathrm{bw}\right)$, fentanyl $\left(1.4 \mu \mathrm{g} \cdot \mathrm{kg}^{-1} \mathrm{bw}\right)$, and succinylcholine $\left(1 \mathrm{mg} \cdot \mathrm{kg}^{-1} \mathrm{bw}\right)$. The patients then underwent orotracheal intubation. Anaesthesia and muscular relaxation were maintained by propofol and pancuronium bromide (20-35 $\mu \mathrm{g} \cdot \mathrm{kg}^{-1}$ bw every $\left.20 \mathrm{~min}\right)$. Controlled ventilation (continuous positive-pressure ventilation (CPPV) at a respiratory frequency $(f \mathrm{R})$ of $10-12$ breaths $\cdot \mathrm{min}^{-1}$, inspiratory-to-expiratory time ratio [I:E] of $1: 2$, tidal volume $(V \mathrm{~T})$ of $10-15 \mathrm{~mL} \cdot \mathrm{kg}^{-1} \mathrm{bw}$, and positive end-expiratory pressure (PEEP) of $5 \mathrm{cmH}_{2} \mathrm{O}$ ) was necessary during the surgical procedure and for a mean duration of $12.5 \mathrm{~h}$ before weaning from the ventilator could begin. Incision was then performed in our hospital by one of two surgeons, at different sites of the abdominal wall. Major resections and tumour debulking procedures were performed at various levels of organ systems.

\section{Outcome of surgery}

The postoperative course of patients was carefully followed, with a daily assessment and recording of respiratory complications and survival. The $24 \mathrm{~h}$ postoperative PA chest radiograph was read by one of us, without information about the patient's treatment. SRCs 
were categorized as follows: 1) absence of clinical-radiological evidence of atelectasis, pleural effusion and/ or infection, or chest radiographic evidence of atelectasis of any size without infection, and/or pleural effusion (Grade 0); 2) chest infection characterized by new occurrence of three or more of the following symptoms or signs: temperature $>37.5^{\circ} \mathrm{C}$ for $24 \mathrm{~h}$ with chest radiographic changes, productive cough, dyspnoea, chest pain or discomfort, and tachycardia (pulse $>100$ beats $\cdot \mathrm{min}^{-1}$ ), or acute respiratory failure characterized by arterial oxygen tension $\left(\mathrm{Pa}_{\mathrm{a}} \mathrm{O}_{2}\right)<6.65 \mathrm{kPa}(50 \mathrm{mmHg})$ and/or arterial carbon dioxide tension $\left(P \mathrm{a}, \mathrm{CO}_{2}\right)>5.98 \mathrm{kPa}(45 \mathrm{mmHg})$ at any time postoperatively, or on routine analysis of arterial blood gas values on day three postoperatively, or by a requirement for intubation (Grade 1).

\section{Statistical methods}

Data are reported as the mean $(\overline{\mathrm{x}})$, standard deviation (SD), and range, unless otherwise indicated. Preoperative anthropometric, clinical and respiratory function variables were compared using analysis of variance (ANOVA) and Bonferroni-Dunn correction in the case of multiple comparisons. Logistic regression analysis [20] (using the Statistica ${ }^{\mathrm{TM}}$ package (v4.1; StatSoft, Tulsa, OK, USA) package) [21] applied to the whole population was performed, to investigate, by univariate test, the dependence of SRCs on each independent variable and to estimate the odds ratios. Finally, a stepwise multiple approach of logistic regression analysis was used to determine the relative usefulness of the entire set of different variables combined, and thus to generate prediction equations for SRCs. A p-value less than 0.05 was considered to be significant.

\section{Results}

\section{Anthropometric data and results of the respiratory ques- tionnaire}

Three hundred and sixty one consecutive patients (248 males (69\%) and 113 females (31\%)) admitted to our hospital for laparotomy, were studied. Their mean age was $64 \pm 11$ yrs (range 25-90 yrs), BMI 26.1 \pm 4.32 $\mathrm{kg} \cdot \mathrm{m}^{-2}$ (range $17-39 \mathrm{~kg} \cdot \mathrm{m}^{-2}$ ), and standing height $1.6 \pm$ $0.1 \mathrm{~m}$ (range 1.4-1.9 m). Preoperatively, a history of current mucous hypersecretion $(\mathrm{CMH})$ and cough was present in $24(7 \%)$ of the 361 patients, $17(71 \%)$ of whom were current smokers. Thirteen $(4 \%)$ of the 361 patients reported very slight to moderate preoperative dyspnoea, according to the Borg scale. Individual demographic data, smoking status, and preoperative clinical evaluation for these patients are presented in table 1 .

\section{Functional patterns}

One hundred and fifty five (43\%) of the 361 patients were functionally normal as assessed by spirometry, 91 (25\%) had a restrictive disorder, 79 (22\%) demonstrated airflow obstruction, 32 had a mixed pattern (9\%),
Table 1. - Patients' demographic data, smoking status and preoperative clinical evaluation

\begin{tabular}{lcrrr}
\hline & \multicolumn{2}{c}{ Male } & \multicolumn{2}{c}{ Female } \\
& $\mathrm{n}$ & $\%$ & $\mathrm{n}$ & $\%$ \\
\hline Tobacco use§ & & & & \\
Lifetime nonsmokers & 40 & 16 & 79 & 70 \\
Former smokers & $135^{*}$ & 54 & 19 & 16 \\
Current smokers & 73 & 29 & 15 & 13 \\
CMH & 17 & 7 & 7 & 6 \\
Dyspnoea & 8 & 3 & 5 & 4 \\
Total & $248^{*}$ & 69 & 113 & 31 \\
\hline
\end{tabular}

All patients were Caucasian. *: one of these died on the fifth postoperative day from acute myocardial infarction and has been excluded from analysis; $§$ : according to American Thoracic Society (ATS) definition [12]. CMH: current mucous hypersecretion.

and four had an isolated impairment of transfer factor (1\%) of unknown origin (tables 2 and 3$)$. TL,CO,sb was altered in 28 of the 79 patients with obstructive disorder $(35 \%)$. Within this dysfunctional group, of the patients with lower than normal TL,CO,sb values, 17 were former and 11 current smokers. Thirty six patients $(46 \%)$ with airflow obstruction and 12 (37\%) with mixed pattern were responding well to inhaled salbutamol. Finally, 15 (19\%) of the obstructed and six (19\%) of the mixed group were suffering from preoperative CMH. Nine patients (11\%) with obstructive defect, two

Table 2. - Preoperative lung function data

\begin{tabular}{lcl}
\hline FEV 1 L & $2.3 \pm 0.7$ & $(0.4-5.0)$ \\
FEV 1 \% pred & $92 \pm 20$ & $(30-145)$ \\
IVC L & $3.2 \pm 0.9$ & $(1.1-6.0)$ \\
FEV $1 /$ IVC \% & $72 \pm 12$ & $(32-99)$ \\
PEF L $\cdot \mathrm{s}^{-1}$ & $6.3 \pm 2.1$ & $(1.9-12.5)$ \\
TLC L & $5.1 \pm 1.1$ & $(2.5-7.9)$ \\
RV L & $1.9 \pm 0.7$ & $(0.4-3.8)$ \\
TL,CO,sb SI & $7.1 \pm 1.8$ & $(2.1-14.2)$ \\
TL,CO,sb \% pred & $92 \pm 16$ & $(44-140)$
\end{tabular}

Values are presented as mean $\pm \mathrm{SD}$, and range in parenthesis. FEV1: forced expiratory volume in one second; IVC: inspiratory slow vital capacity; PEF: peak expiratory flow; TLC: total lung capacity; RV: residual volume; SI: standard international units $\left(\mathrm{mmol} \cdot \mathrm{min}^{-1} \cdot \mathrm{kPa}^{-1}\right) ; T \mathrm{~L}, \mathrm{CO}, \mathrm{sb}$ : single-breath transfer factor of the lung for carbon monoxide; $\%$ pred: percentage of predicted value.

Table 3. - Preoperative pulmonary function patterns and incidence rate of SRCs

\begin{tabular}{|c|c|c|c|c|c|}
\hline \multirow[b]{2}{*}{$\begin{array}{l}\text { Pulmonary } \\
\text { function }\end{array}$} & \multirow{2}{*}{$\begin{array}{c}\text { Patients } \\
n\end{array}$} & \multirow{2}{*}{$\begin{array}{c}\mathrm{CMH} \\
\mathrm{n}\end{array}$} & \multirow{2}{*}{$\begin{array}{c}\text { Dyspnoea } \\
\text { n }\end{array}$} & \multicolumn{2}{|c|}{ SRCs } \\
\hline & & & & $\mathrm{n}$ & $\%$ \\
\hline Normal & $155^{*}$ & 2 & 0 & 4 & 3 \\
\hline Restri & 91 & 1 & 2 & 1 & 1 \\
\hline Obstructed & 79 & 15 & 9 & 35 & 44 \\
\hline Mixed & 32 & 6 & 2 & 8 & 25 \\
\hline Impaired transfer & 4 & 0 & 0 & 1 & 25 \\
\hline
\end{tabular}

factor

*: one of these died on the fifth postoperative day from acute myocardial infarction, and has been excluded from analysis. CMH: current mucous hypersecretion; SRCs: severe respiratory complications. 
of the mixed and two of the restricted group were suffering from preoperative dyspnoea.

\section{Surgical data}

The most frequent site of incision was the median xyphoumbilical line (247 subjects; 68\%) (table 4). The operations performed were major resections for colorectal cancer in $189(52 \%)$. The remaining operations were resections for malignant tumours of the liver and/ or biliary tract (including gall bladder) in 103 cases (28\%), stomach in $48(13 \%)$, pancreas in $20(5 \%)$, and splenectomy for non-Hodgkin lymphoma in one (table 4).

\section{Respiratory morbidity and mortality}

Four patients died within the first 10 days after surgery. One of these died on the fifth postoperative day from acute myocardial infarction following a right hemicolectomy. He was free of SRCs until the time of his death, and has been excluded from the analysis of respiratory morbidity, which is thus restricted to 360 patients. In the three of these 360 patients who died, there was a clear relationship between the surgery and death from SRCs. Two of the three patients (Nos. 3 and 14 amongst obstructive patients not responsive to salbutamol) had undergone partial hepatectomy, and one a splenectomy. Amongst the SRCs associated with mortality were acute respiratory distress syndrome (ARDS) and septic shock in two patients, and rupture of the diaphragm in one. There was no clear relationship between mortality and any individual surgeon, respiratory physician, or the European Clinical Oncology Group (ECOG) status of the patient. There were no further deaths until the 60th postoperative day, and this and all subsequent deaths were considered to be tumour-related rather than the result of laparotomy or intra-abdominal resection. Our patients had a $1 \%$ mortality rate and a $14 \%$ incidence of postoperative SRCs (graded as 0 (absent or normal) and 1 (present or abnormal)) (49 out of 360 patients), with a male:female ratio of 0.86 . Differences in smoking status between the two sexes did not

Table 4. - Surgical data

\begin{tabular}{lccc}
\hline & \multicolumn{2}{c}{ Patients } & SRCs \\
\cline { 2 - 3 } & $\mathrm{n}$ & $\%$ & $\%$ \\
\hline Site of incision & & & \\
$\quad$ Median & $247^{*}$ & 68 & 13 \\
$\quad$ Bilateral subcostal & 68 & 19 & 16 \\
$\quad$ Right subcostal & 46 & 13 & 11 \\
Organ systems & $189 *$ & 52 & 13 \\
$\quad$ Colon-rectum & 103 & 28 & 11 \\
$\quad$ Liver and biliary tract & & & \\
$\quad$ (including gall bladder) & & 13 & 15 \\
$\quad$ Stomach with spleen & 48 & 5 & 20 \\
$\quad \begin{array}{l}\text { Pancreas } \\
\text { Spleen }\end{array}$ & 20 & 0.3 & - \\
\hline
\end{tabular}

*: one of these died on the fifth postoperative day from acute myocardial infarction, and has been excluded from analysis. SRCs: severe respiratory complications. account for the higher incidence rate of SRCs amongst females. Of 49 patients who suffered from SRCs, 33 had undergone median laparotomy, but the highest incidence rate for SRCs was observed amongst subjects who underwent a bilateral subcostal incision (11 out of $68 ; 16 \%)$. On the other hand, pancreatectomy carried the highest incidence (20\%) of postoperative SRCs. The highest complication rate was seen within the obstructive group (35 out of 79 patients; 44\%). For the other patients, $25 \%$ of the mixed group ( 8 out of 32 patients), $3 \%$ of the physiologically normal subjects (4 out of 154 patients), and one patient with abnormal transfer factor had SRCs. Finally, $1 \%$ of the restrictive group (1 out of 91 patients) had SRCs.

\section{Univariate logistic regression analysis}

Table 5 presents the results of the logistic regression analyses applied to the whole of the present series as a single group of 360 patients, irrespective of preoperative functional pattern, performed to investigate the dependence of SRCs on each single input variable and to estimate the odds ratios. Current and former active smoking, and, to a lesser degree, older age were significantly associated with an increased incidence of SRCs. Of the independent variables analysed, low values of FEV1, IVC, FEV1/IVC, and TL,CO,sb were significant predictors of SRCs. However, amongst functional parameters, an abnormally high RV before surgery was the most important predisposing factor for the development of postoperative SRCs. Nevertheless, the two variables most significantly associated with postoperative SRCs were preoperative dyspnoea and, above all, CMH. Conversely, the following factors were not significantly associated with the onset of SRCs: sex, standing height, BMI, TLC, site of surgical incision, and type of surgery.

Table 5. - Results of the univariate logistic regression analyses, with SRCs as categorical dependent variable

\begin{tabular}{lccc}
\hline Factor analysed & OR & $95 \%$ CI & p-value \\
\hline Standing height $(\mathrm{m})$ & 0.15 & $0.00-4.41$ & $\mathrm{NS}$ \\
Age (yrs) & 1.04 & $1.01-1.07$ & 0.01 \\
BMI (kg.m ${ }^{-2}$ ) & 1.00 & $0.93-1.07$ & $\mathrm{NS}$ \\
Smoking current and & 2.94 & $1.87-4.63$ & $<0.0001$ \\
former & & & \\
Female gender & 0.84 & $0.45-1.59$ & $\mathrm{NS}$ \\
Dyspnoea & 44.2 & $5.40-362$ & $<0.001$ \\
CMH & 90.8 & $25.5-323$ & $<0.0001$ \\
FEV1 (L) & 0.06 & $0.03-0.13$ & $<0.0001$ \\
FEV1 (\% pred) & 0.86 & $0.83-0.89$ & $<0.0001$ \\
IVC (L) & 0.35 & $0.23-0.52$ & $<0.0001$ \\
FEV1/IVC & 0.84 & $0.81-0.88$ & $<0.0001$ \\
TLC (L) & 0.84 & $0.64-1.11$ & $\mathrm{NS}$ \\
RV (L) & 12.3 & $6.18-24.6$ & $<0.0001$ \\
TL,CO,sb (SI) & 0.25 & $0.17-0.36$ & $<0.0001$ \\
TL,CO,sb (\% pred) & 0.84 & $0.80-0.88$ & $<0.0001$ \\
Bilateral subcostal & 1.23 & $0.72-2.11$ & $\mathrm{NS}$ \\
incision & & & \\
\hline
\end{tabular}

SRCs: severe respiratory complications; OR: odds ratio; $95 \%$ CI: 95\% confidence interval; Ns: nonsignificant; BMI: body mass index; $\mathrm{CMH}$ : current mucous hypersecretion. For further definitions see legend to table 2 . 


\section{Stepwise multiple logistic regression analysis}

If all significant variables presented in table 5 were entered into the model simultaneously, a small number of covariates were found to be significant. The best predictors of SRCs were CMH, RV, and percentage of predicted values both of FEV1 (FEV1\% pred) and TL,CO,sb ( $T \mathrm{~L}, \mathrm{CO}, \mathrm{sb} \%$ pred). Interestingly, we showed that $\mathrm{CMH}$, when considered on its own, entailed the highest risk for SRCs, and, in conjunction with other covariates (namely $\mathrm{FEV}_{1} \%$ pred and $\mathrm{TL}, \mathrm{CO}, \mathrm{sb} \%$ pred) carried an estimated odds ratio $(\mathrm{OR})$ of $133(\mathrm{p}<0.0001)$. On the other hand, abnormally high RV values and low FEV $1 \%$ pred and TL,CO,sb \% pred values were also strongly predictive for SRCs. Thus, the best equation for the logistic regression (logit $\theta$ ) of the probability of postoperative SRCs utilizing these four covariates was:

$\operatorname{logit} \theta(\mathrm{SRCs})=9.11-0.07 \mathrm{FEV} 1 \%$ pred +1.13 $\mathrm{RV}-0.10 \mathrm{TL}, \mathrm{CO}, \mathrm{sb} \%$ pred $+4.89 \mathrm{CMH}$

where logit $\theta=\log _{\mathrm{e}}(\theta / 1-\theta)$, and $\mathrm{CMH}=0$ if absent and 1 if present.

The finding of $\mathrm{CMH}, \mathrm{RV}, \mathrm{FEV} 1 \%$ pred and TL,CO,sb $\%$ pred values corresponding to various levels of the probability $(\overline{\mathrm{p}})$ of SRCs, as well as the ORs and $95 \%$ CIs of these variables, are presented in tables 6 and 7 , respectively. Some indication of the ability to predict SRCs using these four covariates can be obtained by

Table 6. - Results of the stepwise multiple regression analysis, with SRCs as categorical dependent variable

\begin{tabular}{lccc}
\hline $\begin{array}{l}\text { Factors entered in the } \\
\text { model (logit } \theta)\end{array}$ & OR & $95 \% \mathrm{CI}$ & p-value \\
\hline CMH & 133 & $14.8-1199$ & $<0.0001$ \\
FEV1 (\% pred) & 0.93 & $0.88-0.98$ & $<0.01$ \\
RV (L) & 3.11 & $1.25-7.75$ & 0.01 \\
TL,CO,sb (\% pred) & 0.91 & $0.10-8.16$ & $<0.0001$
\end{tabular}

For definitions see legends to tables 2 and 5. p-values result from testing the hypothesis that $\mathrm{OR}=1$.

Table 7. - $\mathrm{CMH}$ and estimated percentage predicted values both of $F E V_{1}$ and $T L, C O, s b$ for specified values of probability of SRCs

\begin{tabular}{lcc}
\hline Risk factor & $\begin{array}{c}\text { SRCs } \\
\mathrm{n}\end{array}$ & $\begin{array}{c}\text { Probability of } \\
\text { predicted SRCs } \\
(\overline{\mathrm{p}})\end{array}$ \\
\hline CMH & 22 & 0.92 \\
RV & & \\
$\quad>3 \mathrm{~L}$ & 21 & 0.95 \\
$\quad 2.5-2.99 \mathrm{~L}$ & 14 & 0.34 \\
$\quad<2.49 \mathrm{~L}$ & 14 & 0.05 \\
FEV1 & & \\
$\quad<50 \%$ pred & 12 & 1.00 \\
$51-70 \%$ pred & 27 & 0.73 \\
$71-80 \%$ pred & 5 & 0.21 \\
$\quad>80 \%$ pred & 5 & 0.02 \\
TL,CO,sb & & \\
$\quad<60 \%$ pred & 14 & 1.00 \\
$\quad 60-75 \%$ pred & 28 & 0.61 \\
$\quad>75 \%$ pred & 7 & 0.02
\end{tabular}

For definitions see legend to tables 2 and 5 .
Table 8. - Sensitivity, specificity and predictive values for SRCs of logit $\theta$

\begin{tabular}{lccc}
\hline $\begin{array}{l}\text { Prediction of SRCs } \\
\text { (logit } \theta \text { ) }\end{array}$ & & \multicolumn{2}{c}{ Number misclassified } \\
\cline { 3 - 4 } & $\%$ & No SRCs & SRCs \\
\hline Sensitivity & 84 & - & $2 / 43$ \\
$\begin{array}{l}\text { Specificity } \\
\text { Positive predictive value } \\
\text { (accuracy) }\end{array}$ & 99 & $8 / 317$ & - \\
Negative predictive value & 98 & - & - \\
\hline
\end{tabular}

SRCs: severe respiratory complications.

noting that: 1) $\mathrm{CMH}$ was recorded in 22 out of 24 complicated patients; 2) RV absolute value $>3 \mathrm{~L}$ was recorded in 21 out of 49 complicated patients; 3) FEV1 value of $<71 \%$ pred was recorded in 39 out of the 49 severely complicated patients; 4) TL,CO,sb value of $<76$ $\%$ pred was recorded for 42 of the 49 patients who suffered from SRCs. The use of these cut-off values to predict SRCs was, thus, associated with the exclusion of over two thirds of subjects who did not suffer from SRCs (table 8).

\section{Bronchodilator response}

Within the obstructive and mixed groups of patients, comparisons of SRC prevalence amongst responders and nonresponders to salbutamol were made by using Chi-squared test. Interestingly, patients not improving markedly following inhaled bronchodilator $(\triangle \mathrm{FEV} 1$ $<12 \%$ ), had SRCs more frequently compared to responders ( 37 versus $6 ; \chi^{2}=22.6 ; c=0.43 ; p<0.0001$ ), suggesting that a partial reversibility of obstructive defect could be a protective factor against serious complications.

\section{Discussion}

In this study, using the logistic regression analysis approach, we found that the presence of CMH in conjunction with an increase in $\mathrm{RV}$, and, to a lesser extent, low values both of FEV1 and TL,CO,sb are extremely sensitive and specific factors to recognize high-risk patients for SRCs following UAS.

It is well-known that, after laparotomy, respiratory dysfunction often occurs and possibly as a result of pain, residual effects of anaesthetics and muscle relaxants [22], diaphragmatic fatigue [23], and neural reflexes. It is a common misconception that the major mechanism responsible for postoperative atelectasis is retention of tracheobronchial secretions. However, atelectasis commonly occurs in patient without secretions and with normal lungs [25]. On the other hand, anaesthesia is accompanied by a reduction of the rib cage excursions [26], right shift of the pressure-volume curve (reduced "expansion pressure") [27], early airways closure [28], and redistribution of ventilation to the upper lung zones [29]. The increased airway resistance ( $R$ aw) [30] is probably merely reflecting the reduced FRC, which in normal subjects is very close to relaxation volume $(V \mathrm{r})$ of the respiratory system. 
BRISMAR et al. [31], using computed tomography (CT) with transverse exposure of the chest, demonstrated, in more than $90 \%$ of patients with healthy lungs, densities in dependent regions of both lungs during anaesthesia. By applying an external PEEP of $10 \mathrm{cmH}_{2} \mathrm{O}$, the densities were reduced or eliminated, but they reappeared within 1 min after the discontinuation of PEEP. Subsequent morphological analyses in sheep, showed these regions to be atelectatic with minor interstitial oedema and only moderate vascular congestion [32]. If these findings are extrapolated to humans, it can be concluded that anaesthesia causes atelectasis. The rapid appearance of the densities on induction of anaesthesia and after discontinuation of PEEP speaks against slow resorption of gas as the cause of atelectasis, and another, as yet unclear, mechanism has to be found.

Thus, the reduced FRC during anaesthesia does not necessarily produce atelectasis, but there must be an additional factor to produce it. This may be relaxation of the diaphragm, permitting the transmission of the higher intra-abdominal pressure onto the thoracic cavity. Thus, an increased vertical gradient of regional volume has been observed on relaxing the diaphragm from a voluntarily tense state in the awake subjects [33]. These clinical and experimental findings have turned opinion away from atelectasis being the cause of altered lung mechanics and impaired gas exchange during anaesthesia.

Whilst the abdomen remained open, increased impedance of the respiratory system ( $\left.Z_{\mathrm{rs}}\right)$ was found [34]. In fact, it is conceivable that, after abdominal opening, both changes in chest wall tissue viscoelastic properties and a significant increase in total resistance of the respiratory system (Rtot,rs), are inclined to occur. These changes can be closely related to stress relaxation properties of chest wall tissues [34, 35]. However, after abdominal closure, no significant changes in elastance could be detected in rats [36].

After laparotomy, the diaphragm is shifted cranially and the $V$ T contribution of this muscle is greatly reduced [7] because of reflex inhibition (unless it has sustained direct surgical trauma) to contraction [6]. The reduction of the transverse area and volume of the chest (0.1-2.0 $\mathrm{L}$ ), as well as decreased FRC and its relation to closing volume (CV) correlated to arterial hypoxaemia [5], indicate that airway, and possibly alveolar collapse, contribute to the impairment in gas exchange.

In general, if a pulmonary segment remains atelectatic for longer than $72 \mathrm{~h}$, pneumonia is almost certain to develop [37]. However, the risk factors for the progression from atelectasis to pneumonia have not been closely examined. FUJITA and SAKURAI [38] reported that blood loss of more than 1,200 $\mathrm{mL}$ during abdominal surgery was most significantly associated with the development of postoperative pneumonia. In addition, in a series of 2,696 patients, they have pointed out that preoperative use of nebulizers for inhalation therapy, and age over 65 yrs, were associated with several postoperative chest infections.

Many previous studies have shown a predictive value for functional baseline tests (e.g. for FEV1 and FVC), even though a few are rather controversial [39-41]. On the other hand, there have been no studies which have clearly defined a lower limit of FEV1 or FVC, below which a patient should not be subjected to anaesthesia and abdominal surgery. The present study showed the capacity of preoperative $\mathrm{CMH}$, in addition to baseline indices of pulmonary function to predict severe respiratory morbidity following UAS. In this series, most of the variance in respiratory morbidity could be accounted for using the logit $\theta$ equation alone. These findings apply to the entire group of patients in the present study, but we hypothesize that an algorithm of such remarkable accuracy could also be useful to detect high-risk patients in other series. This index incorporates, in a logical way, elements of ventilation (RV and FEV1), gas exchange properties of the lung ( $T \mathrm{~L}, \mathrm{CO}, \mathrm{sb})$, as well as an ongoing clinical symptom $(\mathrm{CMH})$. An advantage is that it allows the use of percentage predicted rather than absolute values for FEV1 and TL,CO,sb. This enhances its applicability to patients across a wide range of ages and heights, and possibly across gender as well.

The present study confirms that the obstructive component of the ventilatory defect and pulmonary hyperinflation are both important risk factors during UAS but, above all, that $\mathrm{CMH}$ probably play a crucial role in postlaparotomy SRCs pathogenesis. These findings are in keeping with those of DiLworth and White [42] and are also consistent with the hypothesis that during acute inflammatory exacerbations, chronic obstructive pulmonary disease (COPD) patients with preoperative airflow obstruction and hyperinflation would be particularly prone to develop SRCs following UAS. On the other hand, it seems to be important to discriminate the subgroups with lower responsiveness to bronchodilator amongst obstructed and mixed patients, since these subjects might more frequently suffer from postlaparotomy SRCs. However, data concerning the degree of hyperinflation amongst the present patients should be treated with a modicum of caution, because of the low accuracy of the $\mathrm{N}_{2}$ wash-out method to measure lung volumes.

A reduction in TL,CO,sb is usually present in patients with symptomatic COPD. Impairment of transfer factor is considered the best functional indicator of the presence and severity of emphysema, being positively correlated with underlying CT changes of disease [43]. Indeed, COPD patients with emphysema did appear particularly prone to SRCs. It is tempting to attribute this, at least in part, to the greater mechanical impairment of diaphragmatic function in these patients, compared to those with "isolated" chronic bronchitis or asthma. Nevertheless, both the lowering of pressure difference between peritoneum and pleura $(\Delta P \mathrm{di})$ due to the flattening of the diaphragm [44], and the "intrinsic-PEEP" (auto-PEEP) phenomenon of emphysematous patients [45] should partially act against persistence of atelectasis during consciousness. The possible explanation(s) of this behaviour, as well as the importance of surgical transection of the transversus abdominis muscle (which many COPD patients contract during expiration) [46], are as yet unclear.

In summary, we have found that chronic hypersecretion of mucus and three respiratory function variables have a significant predictive capacity for severe respiratory complications following upper abdominal surgery. We consider that our algorithm may be a powerful new predictor of postoperative pulmonary morbidity, that 
warrants evaluation in different populations of patients undergoing upper abdominal surgery to further assess its general applicability.

\section{References}

1. Pasteur W. Active lobar collapse of the lung after abdominal operations: a contribution to the study of postoperative lung complications. Lancet 1910; 2: 1080-1083.

2. Beecher HK. The measured effect of laparotomy on the respiration. J Clin Invest 1933; 12: 639-650.

3. Latimer RG, Dickman M, Day WC, Gunn ML, Schmidt $\mathrm{CD}$. Ventilatory patterns and pulmonary complications after upper abdominal surgery determined by preoperative and postoperative computerized spirometry and blood gas analysis. Am J Surg 1971; 122: 622-632.

4. Ali J, Khan TA. The comparative effects of muscle transection and median upper abdominal incisions on postoperative pulmonary function. Surg Gynecol Obstet 1979; 148: 863-866.

5. Alexander JI, Spencer AA, Parikh RK, Stuart B. The role of airway closure in postoperative hypoxaemia. $\mathrm{Br}$ J Anaesth 1973; 45: 34-40.

6. Dureuil B, Viires N, Cantineau J-P, Aubier M, Desmonts JM. Diaphragmatic contractility after upper abdominal surgery. J Appl Physiol 1986; 61(5): 1775-1780.

7. Simonneau G, Vivien A, Sartene R, et al. Diaphragm dysfunction induced by upper abdominal surgery. Am Rev Respir Dis 1983; 128: 899-903.

8. American College of Physicians Position Paper. Preoperative pulmonary function testing. Ann Intern Med 1990; 112: 793-794

9. Wightman JAK. A prospective survey of the incidence of postoperative pulmonary complications. Br J Surg 1968; 55: 85-91.

10. Laszlo G, Archer GG, Darrell JH, Dawson JM, Fletcher $\mathrm{CM}$. The diagnosis and prophylaxis of pulmonary complications of surgical operations. Br J Surg 1973; 602: 129-134.

11. Borg G, Noble B. Perceived exertion. In: Wilmore HH, ed. Exercise and sports sciences reviews. Vol. 2. New York, Academic Press, 1974; pp. 131-153.

12. Ferris BG. Epidemiology standardization project. Am Rev Respir Dis 1978; 118: 1-120.

13. Garrow JS. Grades of obesity as defined by body mass index. In: Garrow JS, ed. Treat Obesity Seriously. Edinburgh, Churchill Livingstone, 1981; pp. 3-15.

14. American Thoracic Society. Standardization of spirometry. 1994 update. Am J Respir Crit Care Med 1995; 152: $1107-1136$

15. Quanjer PH, Tammeling GJ, Cotes JE, Pedersen OF, Peslin R, Yernault J-C. 1993 update. Lung volumes and forced ventilatory flows. Report Working Party, "Standardization of Lung Function Tests". European Coal and Steel Community. Official statement of the European Respiratory Society. Eur Respir J 1993; 6 (Suppl. 16); 540.

16. American Thoracic Society. Lung function testing: selection of reference values and interpretative strategies. $A m$ Rev Respir Dis 1991; 144: 1202-1218.

17. Cotes JE. Assessing bronchodilatation. In: Cotes JE, ed. Lung Function: Assessment and Application in Medicine. 5th Edn. Oxford, Blackwell Scientific Publications, 1993; pp. 145-149.

18. Forster RE, Fowler WS, Bates DV, Van Lingen B. The absorption of carbon monoxide by the lungs during breathholding. J Clin Invest 1954; 33: 1135-1145.

19. Cotes JE, Chinn DJ, Quanjer PH, Roca J, Yernault J-C. 1993 update. Standardization of the measurement of transfer factor (diffusing capacity). Report Working Party, "Standardization of Lung Function Tests". European Coal and Steel Community. Official statement of the European Respiratory Society. Eur Respir J 1993; 6 (Suppl. 16); 41-52.

20. Hosmer DW, Lemeshow S. Applied logistic regression. New York; John Wiley \& Sons Inc., 1989.

21. Statistica ${ }^{\mathrm{TM}}$ v.4.1, StatSoft ${ }^{\mathrm{TM}}$, Tulsa, OK, USA.

22. Craig DB. Postoperative recovery of pulmonary function. Anesth Analg 1981; 60: 46-52.

23. Aubier M, De Troyer A, Sampson M, Macklem PT, Roussos C. Aminophylline improves diaphragmatic contractility. N Engl J Med 1981; 305: 249-252.

24. Duron P. Intercostal and diaphragmatic muscle endings and afferents. In: Hornbein TF, ed. Regulation of Breathing. New York, Dekker, 1981; pp. 473-540.

25. Tisi GM. Preoperative evaluation of pulmonary function: validity, indications and benefits. Am Rev Respir Dis 1979; 119: 293-310.

26. Jones JG, Faithfull D, Jordan C. Rib cage movement during halothane anesthesia in man. Br J Anaesth 1979; 51: 399-407.

27. Westbrook PR, Stubbs SE, Sessler AD, Rehder K, Hyatt RE. Effects of anesthesia and muscle paralysis on respiratory mechanics in normal man. J Appl Physiol 1973; 34: 81-86.

28. Juno J, Marsh HM, Knopp TJ, Rehder K. Closing capacity in awake and anesthetized-paralyzed man. $J$ Appl Physiol: Respirat Environ Exercise Physiol 1978; 44: 238-244.

29. Rehder K, Hatch DJ, Sessler AD, Fowler WS. The function of each lung of anesthetized and paralyzed man during mechanical ventilation. Anesthesiology 1972; 37: $16-26$.

30. Clements JA, Sharp JT, Johnson RP, Elam JO. Estimation of pulmonary resistance by repetitive interruption of airflow. J Clin Invest 1959; 38: 1262-1270.

31. Brismar B, Hedenstierna G, Lundqvist H, Strandberg Å, Svensson L, Tokics L. Pulmonary densities during anesthesia with muscular relaxation: a proposal of atelectasis. Anesthesiology 1985; 62: 422-428.

32. Hedenstierna G, Lundqvist $\mathrm{H}$, Lundh $\mathrm{B}$, et al. Pulmonary densities during anaesthesia: an experimental study on lung morphology and gas exchange. Eur Respir $J$ 1989; 2: 528-535.

33. Roussos CS, Fukuchi Y, Macklem PT, Engel LA. Influence of diaphragmatic contraction on ventilation distribution in horizontal man. J Appl Physiol 1976; 40: 417-424.

34. Zin WA, Martins MA, Silva PRM, Sakae RS, Carvalho ALI, Saldiva PHN. Effects of abdominal opening on respiratory system mechanics in ventilated rats. $J$ Appl Physiol 1989; 66: 2496-2501.

35. D'Angelo E, Calderini E, Torri G, Robatto FM, Bono D, Milic-Emili J. Respiratory mechanics in anesthetized paralyzed humans: effects of flow, volume and time. $J$ Appl Physiol 1989; 67: 2556-2564.

36. Moreira LFP, Aires ST, Gobbi CF, Saldiva PHN, Zin WA. Respiratory system, lung, and chest wall mechanics after longitudinal laparotomy in rats. Eur Respir J 1995; 8: 105-108.

37. Pellegrim CA. Postoperative complications. In: Way LW, ed. Current Surgical Diagnosis and Treatment. East 
Norwalk, Connecticut, Appleton \& Lange, 1988: pp. 23-39.

38. Fujita T, Sakurai K. Multivariate analysis of risk factors for postoperative pneumonia. Am J Surg 1995; 169: 304-307.

39. Money SR, Rice K, Crockett D, et al. Risk of respiratory failure after repair of thoracoabdominal aortic aneurysms. Am J Surg 1994; 168: 152-155.

40. Iannuzzi C, Terracciano CA, Santangelo E, Leone L, Gallo C. Multifactorial surgical risk index of the development of respiratory complications. Ann Ital Chir 1992; 63: 439-442.

41. Williams-Russo P, Charlson ME, MacKenzie CR, Gold JP, Shires GT. Predicting postoperative pulmonary complications: is it a real problem? Arch Int Med 1992; 152: 1209-1213.

42. Dilworth JP, White RJ. Postoperative chest infection after upper abdominal surgery: an important problem for smokers. Respir Med 1992; 86: 205-210.

43. Foster WL Jr, Pratt PC, Roggli VL, Godwin JD, Halvorsen RA Jr, Putman CE. Centrilobular emphysema: CT- pathologic correlation. Radiology 1986; 159: 27-32.

44. Loring SH, Mead J. Action of the diaphragm on the rib cage inferred from a force-balance analysis. J Appl Physiol: Respirat Environ Exercise Physiol 1982; 53: 756-760.

45. Pepe PE, Marini JJ. Occult positive end-expiratory pressure in mechanically-ventilated patients with airflow obstruction: the auto-PEEP effect. Am Rev Respir Dis 1982; 126: 166-170.

46. Ninane V, Rypens F, Yernault JC, De Troyer A. Abdominal muscle use during breathing in patients with chronic airflow obstruction. Am Rev Respir Dis 1992; 146: 16-21. 